\title{
Morbidity pattern and outcome in patients admitted in a paediatric intensive care unit: Experience of a hospital attached to a medical college in rural Maharashtra, India
}

\author{
*Subhash Shankar Poyekar ${ }^{1}$ \\ Sri Lanka Journal of Child Health, 2021; 50(4): 655-660 \\ DOI: http://doi.org/10.4038/sljch.v50i4.9857
}

\begin{abstract}
Introduction: Critically ill children require treatment in an intensive care unit which is not easily available in rural areas and costly resulting in more deaths in rural parts of India. The knowledge of pattern of disease prevalent in the local community plays an important role in planning appropriate health care facilities. Outcome findings help in evaluation of current medical practices and carrying out changes if necessary, leading to better patient care.
\end{abstract}

Objectives: To analyse morbidity pattern and outcome in patients admitted in a Paediatric Intensive Care Unit (PICU) of a hospital in rural Maharashtra.

Method: Descriptive data were collected retrospectively from the hospital medical records from January 2017 to December 2018 and analysed for morbidity pattern and outcome in children admitted in the PICU.

Results: A total of 2386 children were admitted and treated in the PICU during the 2-year period. Mean age of the studied patients was $40.2 \pm 42$ months; $34 \%$ were infants and $58.9 \%$ were males. The mean length of stay (LOS) in PICU was $4.81 \pm$ 4.89 days. Diagnoses included respiratory infection $(27.3 \%)$, infectious diseases $(20.5 \%)$, neurological disorders (18.2\%), gastrointestinal (10.5\%), haematological $(5.8 \%)$, renal/endocrinal $(3.2 \%)$, cardiovascular $(3.1 \%)$, and others $(10.7 \%)$. Other causes included acute poisoning, snake / scorpion bite, trauma and foreign body ingestion / aspiration. The overall mortality rate was $9 \%$.

${ }_{1}$ Associate Professor, Department of Paediatrics, Rural Medical College, Loni, Maharashtra. India *Correspondence: dr.subhashp18@gmail.com

https://orcid.org/0000-0003-4450-9960

(Received on 19 October 2020: Accepted after revision on 18 December 2020)

The authors declare that there are no conflicts of interest.

Personal funding was used for the project.

Open Access Article published under the Creative

Commons Attribution CC-BY cC (i) License
Conclusions: The present study reveals that the most susceptible age group was under-five year old children. Respiratory illnesses and infectious diseases were the major causes.

(Key words: Cardiovascular, Infectious diseases, Morbidity pattern, Outcome, PICU).

\section{Introduction}

In the developing world, morbidity and mortality in under-five year old children is an important public health problem ${ }^{1}$. Paediatric intensive care unit (PICU) is set aside for managing children with lifethreatening illnesses ${ }^{2}$. The aim of a PICU is early intervention and quality care to achieve a good outcome. There is increased survival of critically ill children, with advances in intensive care facilities ${ }^{3}$. Outcome depends on the underlying nature of the disease, associated co-morbidities, clinical condition of the patient at presentation, infrastructure and the quality of care provided in the unit ${ }^{4}$. Study of the morbidity pattern among the treated children provides information of the diseases in the community and facilitates a strategy to deal with them and make the PICU more adaptive for the population catered.

\section{Objectives}

To analyse morbidity pattern and outcome in patients admitted in a PICU of a hospital in rural Maharashtra.

\section{Method}

A retrospective record-based study was carried out to review the admissions to the PICU of a hospital attached to a post-graduate teaching institute located in a rural part of Maharashtra. The hospital has a well-equipped six-bed PICU, and a 6-bed High Dependency Unit (HDU) which admits paediatric patients $<12$ years of age. Data of admissions in PICU from January 2017 to December 2018 (2-year period) were collected, which included age, gender, diagnosis, duration of stay, advanced management provided in PICU and the outcome. Outcome was classified as transfers to main paediatric ward, discharge against medical advice (DAMA), referral discharge and death. All patients in PICU were treated according to a written standard protocol. 
Ethical issues: Approval was obtained from the Ethical Committee of Pravara Institute of Medical Sciences-Deemed University (No. PIMS/DR/ $\mathrm{RMC} / 2019 / 305)$. As this was a retrospective study informed consent was not possible. Confidentiality was assured.

Statistical analysis: Data were analysed using Microsoft Office Excel version 2007 and statistical package for social science, version 17.0. Nominal data were compared using the Chi square test. $p$ $<0.05$ was considered significant.

\section{Results}

A total of 2386 children who received care in the PICU during the 2-year period were enrolled. Agewise and gender-wise distribution of study subjects in the 2 year study period are shown in Figures 1 and 2. Majority of them were under-5 year old children. The proportion of infants getting admitted had increased in 2018, so also more male children required admission during 2018 as compared to the previous year. Month-wise admissions to PICU are shown in Figure-3. There were more admissions from August to October.

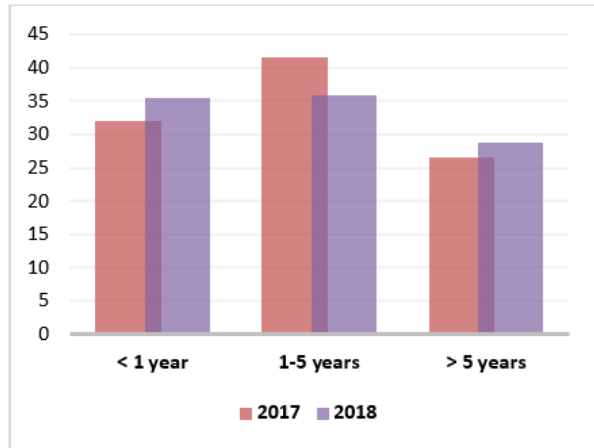

Figure 1: Age-wise distribution of study subjects

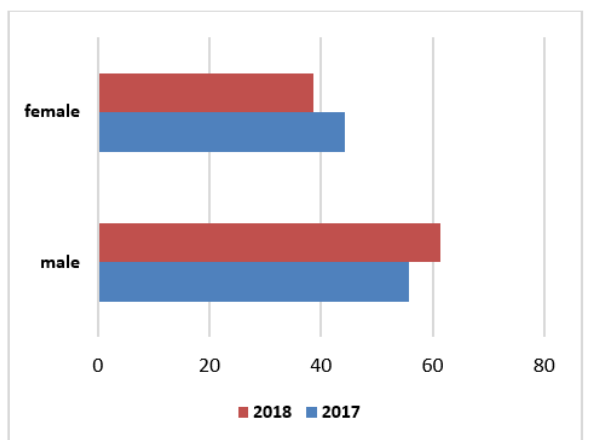

Figure 2: Gender-wise distribution of study subjects

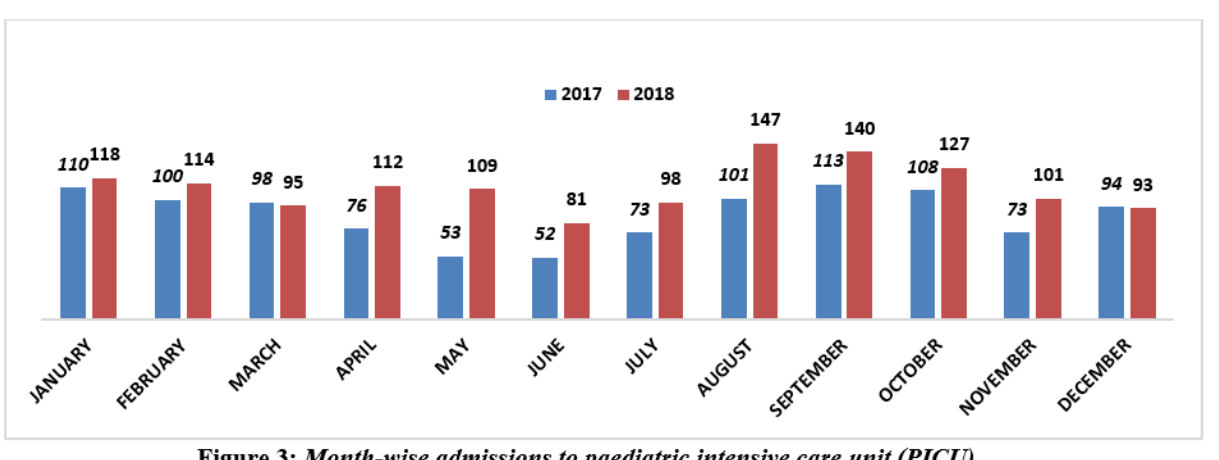

Figure 3: Month-wise admissions to paediatric intensive care unit (PICU)

Diagnoses in children admitted in PICU are shown in table 1. Respiratory system affection was the leading cause of morbidity in children, followed by infectious diseases and neurological problems. Acute poisoning (ingestion/inhalation) and snake / scorpion bite were the major causes for severe morbidity requiring PICU admission/care. Accidental ingestion/aspiration of foreign body and trauma were other the non-infectious/non-systemic causes for admission and care in the PICU.

Table 1: Disease pattern in patients admitted to paediatric intensive care unit (PICU)

\begin{tabular}{|l|c|c|c|c|c|c|}
\hline \multicolumn{1}{|c|}{ Diagnosis } & \multicolumn{2}{c|}{$\mathbf{2 0 1 7}$} & \multicolumn{2}{c|}{$\mathbf{2 0 1 8}$} & \multicolumn{2}{c|}{ Total } \\
\cline { 2 - 7 } & $\mathbf{N = 1 0 5 1}$ & $\mathbf{\%}$ & $\mathbf{N = 1 3 3 5}$ & $\mathbf{\%}$ & $\mathbf{N = 2 3 8 6}$ & $\mathbf{\%}$ \\
\hline Respiratory infections & 260 & 24.7 & 392 & 30.9 & 652 & 27.3 \\
\hline Infectious disease & 198 & 18.8 & 290 & 21.7 & 488 & 20.5 \\
\hline Neurological problems & 181 & 17.2 & 254 & 19.0 & 435 & 18.2 \\
\hline Gastrointestinal diseases & 136 & 12.9 & 115 & 8.6 & 251 & 10.5 \\
\hline Poisoning, bites (snake/scorpion) & 99 & 9.42 & 82 & 6.14 & 181 & 7.6 \\
\hline Haematological & 63 & 5.8 & 68 & 5.1 & 131 & 5.5 \\
\hline Renal and metabolic disorders & 43 & 4.1 & 34 & 2.5 & 77 & 3.2 \\
\hline Cardiovascular system & 31 & 2.9 & 42 & 3.1 & 73 & 3.1 \\
\hline Trauma, foreign body ingestion /aspiration & 34 & 3.2 & 47 & 2.2 & 81 & 3.4 \\
\hline Others & 06 & 0.6 & 11 & 0.8 & 17 & 0.7 \\
\hline
\end{tabular}


Length of stay (LOS) in the PICU is shown in Figure 4. Nearly half of the children stayed in the PICU for less than 3 days, whereas the proportion of children requiring prolonged intensive care increased during 2018.

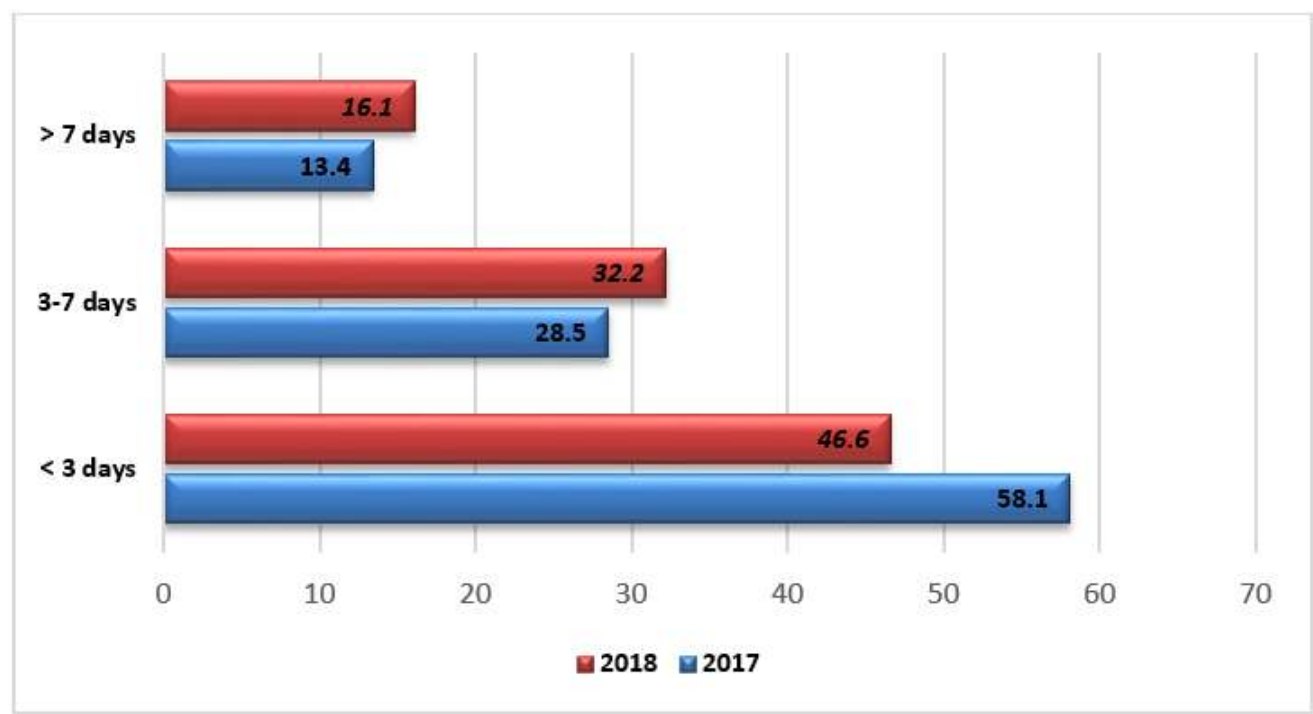

Figure 4: Length of stay of patients in the paediatric intensive care unit (PICU)

Year-wise immediate outcome of management in study subjects is shown in table 2. It showed increase in mortality during 2018, however the proportion of children leaving against medical advice (LAMA) had shown a decline.

Table 2: Year wise outcome in study subjects

\begin{tabular}{|l|c|c|c|c|c|c|}
\hline \multirow{2}{*}{} & \multicolumn{2}{|c|}{$\mathbf{2 0 1 7}$} & \multicolumn{2}{|c|}{$\mathbf{2 0 1 8}$} & \multicolumn{2}{c|}{ Total } \\
\cline { 2 - 7 } & $\mathbf{N}$ & $\mathbf{\%}$ & $\mathbf{N}$ & $\mathbf{\%}$ & $\mathbf{N}$ & $\mathbf{\%}$ \\
\hline Transferred \& Discharged from Wards & 868 & 82.6 & 1159 & 86.8 & 2027 & 85 \\
\hline Expired & 75 & 7.1 & 140 & 10.5 & 215 & 9.0 \\
\hline Discharged from PICU & 102 & 9.7 & 34 & 2.5 & 136 & 5.7 \\
\hline Left against Medical Advice ( LAMA) & 6 & 0.6 & 2 & 0.1 & 8 & 0.3 \\
\hline
\end{tabular}

Determinants of treatment outcome are shown in table 3 . Overall mortality was $9 \%$ with marginally higher proportion amongst male children. The highest mortality was seen in infants. Better survival was observed in children who showed response to the treatment on day one of admission. Major causes of death were severe respiratory tract infection/diseases and sepsis.

Table 3: Socio-demographic variables and outcome in patients admitted in PICU

\begin{tabular}{|c|c|c|c|c|}
\hline \multirow[t]{2}{*}{ Variable } & \multicolumn{2}{|c|}{ Outcome n (\%) } & \multirow[b]{2}{*}{$\begin{array}{c}\text { Total } \\
(n=2386)\end{array}$} & \multirow[t]{2}{*}{ *P value } \\
\hline & $\begin{array}{l}\text { Survival } \\
(n=2171)\end{array}$ & $\begin{array}{c}\text { Death } \\
(n=215)\end{array}$ & & \\
\hline \multicolumn{5}{|l|}{$\operatorname{Sex}$} \\
\hline $\mathrm{M}$ & $1295(92.17 \%)$ & $110(7.83 \%)$ & 1405 & \multirow[t]{2}{*}{0.019} \\
\hline $\mathrm{F}$ & $876(89.3 \%)$ & $105(10.7 \%)$ & 981 & \\
\hline \multicolumn{5}{|l|}{ Age group (months) } \\
\hline$<12$ & $703 \quad(86.8 \%)$ & $107(13.2 \%)$ & 810 & \multirow{3}{*}{0.0001} \\
\hline $12-59$ & $850 \quad(93.6 \%)$ & $65(6.4 \%)$ & 915 & \\
\hline$>60$ & $618 \quad(93.5 \%)$ & $43(6.5 \%)$ & 661 & \\
\hline \multicolumn{5}{|l|}{ Length of stay (days) } \\
\hline$<1$ & $252(87.8 \%)$ & $35(12.2 \%)$ & 287 & \multirow{3}{*}{$<0.0001$} \\
\hline $2-7$ & $1463(91.84 \%)$ & $130(8.16 \%)$ & 1593 & \\
\hline$>7$ & $456(90.12 \%)$ & $50(9.88 \%)$ & 506 & \\
\hline
\end{tabular}




\section{Discussion}

During the study period 2386 children in the age group of more than 28 days to 12 years were admitted into the PICU. Of them, 1405 (58.9\%) were males with a $\mathrm{M}$ : $\mathrm{F}$ ratio of $1.43: 1$, similar to other tertiary level PICUs ${ }^{4,5}$. Male preponderance in admissions may be caused by biological vulnerability of boys to infection. Tyagi $\mathrm{BB}$, et al found that more boys than girls were admitted to hospital for varied complaints, suggestive of a gender bias $^{6}$. In contrast, a study from South India found that more female patients were treated in the $\mathrm{PICU}^{7}$.

The mean age of study subjects was $40.2 \pm 42$ months, which is comparable to another study ${ }^{4}$. There were 1725 (72\%) children under the age of 5 years, similar to observations in a study by Jyothi $\mathrm{AK}$, et $a l^{8}$. Maximum numbers of patients viz. 915 $(38.4 \%)$ were in the $1-5$ year age group. This was followed by infantile age group which constituted $810(34 \%)$ cases. Similar observations have been reported $^{7}$. However, in another study, the maximum numbers of patients were in the infantile age group ${ }^{9}$ and Nirmala $\mathrm{C}$, et al found that the most common age group of admitted children wase 5 years and above ${ }^{10}$.

This study revealed that respiratory $(27.3 \%)$, infectious diseases $(20.5 \%)$ and neurological diseases $(18.2 \%)$ were the major causes of admission. Other systemic diseases were diagnosed in $21.3 \%$ of children. Respiratory diseases being the leading cause for PICU admission is similar to some studies ${ }^{11,12}$. However, cardiovascular disease $(41.1 \%)$ was the most common disease reported by Blesing I, et $a l^{4}$. Infectious disease was the leading cause of admission in the PICU in a study conducted in Odisha ${ }^{3}$ and nervous system disorders was major cause in a study by Jain $\mathrm{S}$ et $a l^{9}$. Respiratory infections was the predominant cause for admission; which could be a reflection of disease prevalence in the community. In the present study, infectious diseases was the next common cause of admission but a specific causative agent could not be identified in all the cases due to limitation of diagnostic facilities.

Almost five percent of paediatric emergency admissions was because of acute poisoning. Similar finding had been reported in a South Indian study ${ }^{13}$. It chiefly comprised accidental ingestion of household products and insecticides. It could be due to children being from agrarian families and to insecticides and kerosene being stored at home with easy accessibility to them. Snake bite, scorpion sting and unknown bites were also seen in significant number of patients $(3 \%)$. This finding in our study could be attributed to the fact that the majority of them reside in a rural area with poor housing conditions, reptiles having resting places near to their houses.

Substantial numbers of children were admitted with foreign body ingestion/aspiration. Most of them were below 2 years of age. This may be because their parents were working in the field and unable to provide constant supervision. These children play in open areas and hence have access to small particles and nuts / beans. Trauma-related cases constituted a sizeable proportion of admissions into the PICU and were made up of road traffic accidents, head injuries, falls from height and other forms of trauma. This could be due to increase in number of vehicles on road as means of transportation and risky/ adventurous behaviour in growing children.

In this study we analysed seasonal trends/variations of admission rate. It was observed that the number of cases started increasing from August and remained at a high level till October in both years. Respiratory (viral) illnesses mainly contributed to the increased number. The next peak was seen in late winter. This sudden spurt in the cases may be attributed to an outbreak of viral illnesses and vector borne diseases in the surrounding areas.

The mean length of stay (LOS) in the PICU was $4.81 \pm 4.89$ days (range, $1-53$ days). Nearly half of the patients stayed for less than 72 hours. In a study by Haftu $\mathrm{H}$, et $a l^{14}$, the mean ICU stay was $4.9 \pm$ 5.8 days (range 1-30 days) with $61 \%$ of them staying for 2-7 days. An Indian study by Khilnani $\mathrm{P}$, et $a l^{15}$ reported that the mean duration of stay was $4.52 \pm 2.6$ days. In contrast, a study conducted by Sahoo $\mathrm{B}$, et $a l^{3}$ reported that the mean duration of stay was $3.7 \pm 2.5$ days.

The clinical condition of 2163 (90.7\%) patients improved and they were transferred to the paediatric wards for completion of treatment and were eventually discharged. There was a significant decrease in the number of patients leaving against medical advice in 2018.

The overall mortality was $9 \%$, similar to a study by Haftu $\mathrm{H}$, et $a l^{14}$. This value is higher than the mortality rate $(4.1 \%)$ documented by Sahoo B, et $a l^{12}$. It is, however, less than the mortality rate reported by Mridha D et al ${ }^{11}(20.9 \%)$ and Bellad R, et $a l^{16}(16.7 \%)$. Lower mortality may be due to adequate manpower and availability of advanced equipment and provision of continuous medical education on paediatric critical care from time to time for the staff by the institution. Amongst those who died $51.2 \%$ were males and $48.8 \%$ were females, with their mean age being 30 months. There was an increase in percentage of patients with adverse outcome in 2018 as compared to the 
previous year, which may be because of increase in number of patients brought to the PICU in a very critical state, requiring ventilator support and inotropes.

Major causes of death were respiratory infections, sepsis, meningitis/ encephalitis, cardiogenic shock and renal/metabolic disorders. In the study by Roy $\mathrm{N}$, et $a l^{17}$, septicaemia was the leading cause of death, followed by meningitis and respiratory infections. Infantile age group, female gender and LOS less than 24 hours were risk factors for mortality.

\section{Conclusions}

In this study under-five year old children were the vulnerable population with male preponderance. Respiratory infections and infectious diseases were the leading causes of admission with severe respiratory infection and sepsis the leading causes for death. Acute poisoning, bites (snake/scorpion), foreign body ingestion and aspiration substantially contributed to morbidity and mortality amongst rural children. Overall mortality was $9 \%$. Infantile age group, female gender and LOS less than 24 hours were risk factors for mortality.

\section{References}

1. UNICEF. The state of the world's children 2014: every child counts: revealing disparities, advancing children's rights. New York: United Nations Children's Fund 2014:2-4.

2. Manimala R, Suhasini T. Organization of intensive care unit and predicting outcome of critical illness, India. Indian Journal of Anesthesia 2003; 47(5): 328-37.

3. Sahoo B, Patnaik S, Mishra R, Jain MK. Morbidity pattern and outcome of children admitted to a paediatric intensive care unit of Eastern India. International Journal of Contemporary Pediatrics 2017; 4: 486-9. https://doi.org/10.18203/23493291.ijcp20 170694

4. Blessing I. Abhulimhen-Iyoha BI, Pooboni SK, Vuppali NK. Morbidity pattern and outcome of patients admitted into paediatric ICU in India. Indian Journal of Clinical Medicine 2014; 51: 5. https://doi.org/10.4137/IJCM.S13902

5. Haque A, Siddiqui NR, Jafri SK, Hoda M, Bano S, Asad Mian. Clinical profiles and outcomes of children admitted to the paediatric intensive care unit from the emergency department. Journal of College of Physicians and Surgeons Pakistan 2015: 25(4); 301-3.

6. Tyagi BB, Haroon AS, Negi VK, et al. Morbidity patterns amongst hospitalized children in a secondary care hospital of Uttarakhand, India. International Journal of Community Medicine and Public Health 2016; 3(4): 837-44. https://doi.org/10.18203/23946040.ijcmph 20160913

7. Maheswari K, Sharma N. Clinical profile and outcome of patients admitted to paediatric intensive care unit in a tertiary care teaching hospital of Puducherry, India. International Journal of Contemporary Pediatrics 2020; 7:1280-3. https://doi.org/10.18203/23493291.ijcp20 202134

8. Jyothi AK, Ankireddy K. A study on clinical profile and outcome of patients in PICU (paediatric intensive care unit) at tertiary care unit. International Journal of Contemporary Pediatrics 2019; 6: 757-60. https://doi.org/10.18203/23493291.ijcp20 190725

9. Jain S, Bhalke S, Srivastava A. A study of morbidity pattern in PICU at tertiary care center. Journal of Pediatric Critical Care 2018; 5(5): 23-5.

https://doi.org/10.21304/2018.0505.00420

10. Nirmala C, Manjula MR, Prasanna CL, et al. Morbidity profile among children admitted to a tertiary care hospital at Nellore, Andhra Pradesh. Journal of Evidence Based Medicine and Healthcare 2016; 3(57): 2975-8.

https://doi.org/10.18410/jebmh/2016/648

11. Mridha D, SahaS, Ganguly S, Bose K. A retrospective evaluation of morbidity pattern and outcome of patients admitted into a paediatric intensive care unit in India. JMSCR 2017; 5(1): 30586-90. https://doi.org/10.18535/jmscr/v5i11.132

12. Shah GS, Shah BK, Thapa A, Shah L, Mishra OP. Admission patterns and outcome in a paediatric intensive care unit in Nepal. British Journal of Medical Research 2014; 4(30): 4939-45. https://doi.org/10.9734/BJMMR/2014/103 18 
13. Earan SK, Dhandapani L, Arunagirinathan A, Kantamneni S. Clinical spectrum and epidemiological profile of patients admitted to paediatric intensive care unit at a tertiary care centre in South India. International Journal of Scientific Study 2016; 4(3):187-91.

14. Haftu H, Hailu T, Medhaniye A, Gtsadik T. Assessment of pattern and treatment outcome of patients admitted to paediatric intensive care unit, Ayder Referral Hospital,Tigray, Ethiopia, 2015. BMC Research Notes 2018; 11:339. https://doi.org/10.1186/s13104-018-34324

PMid: 29793551 PMCid: PMC5968617

15. Khilnani $\mathrm{P}$, Sarma $\mathrm{D}$, Singh $\mathrm{R}$ et al. Demographic profile and outcome analysis of tertiary level pediatric intensive care unit. Indian Journal of Paediatrics 2004; 71:587-91.

https://doi.org/10.1007/BF02724117

PMid: 15280607 PMCid: PMC7102310
16. Bellad R, Rao S, Patil VD, Mahantshetti NS. Outcome of intensive care unit patients using paediatric risk of mortality (PRISM) score. Indian Pediatrics 2009; 46:1091-2.

17. Roy RN, Shrivastava P, Das DK, et al. Burden of hospitalized paediatric morbidity and utilization of beds in a tertiary care hospital of Kolkata, India. Indian Journal of Community Medicine 2012; 37(4): 252-255. https://doi.org/10.4103/0970-0218.103474 PMid: 23293440 PMCid: PMC3531019 